requirements, these Diplomates are eligible to remain on track for the 3-year extension of their current certificate, creating a 10-year certificate. The 2004 Diplomates are the second group to complete Stage One, almost matching the number of 2003 Diplomates who successfully completed Stage One the previous year. Of the 2004 Diplomates, 80\% have successfully completed Stage One requirements, compared to $81 \%$ of 2003 Diplomates who successfully completed Stage One requirements.

The first 3-year stage of the MC-FP process requires completing either 3 Part II Modules (SAMs), or 2 Part II Modules and 1 Part IV Module (PPM or approved alternate). The ABFM recently announced that all participants who begin MC-FP during 20042010 will have the choice of completing 2 Part II modules and 1 Part IV module or 3 Part II modules to fulfill Stage One requirements.

Stage Two and Stage Three both require the completion of 2 Part II Modules (SAMs) and 1 Part IV Module (PPM or approved alternate). The 2004 group must successfully complete Stage Two requirements by December 31, 2010, after which Diplomates will earn the 3 -year extension to their 7-year certificate. These requirements may be completed anytime prior to the deadline, and the ABFM Web site will immediately indicate the 3-year extension; however, the 10-year certificate will not be mailed to the Diplomates until the end of Stage Two (December 31, 2010).

MC-FP consists of 4 elements, each designed to assess 4 important physician characteristics: professionalism (Part I), self-assessment and lifelong learning (Part II), cognitive expertise (Part III), and performance in practice (Part IV). The requirements for each of the three 3-year Stages, as explained above, fulfill Part II and Part IV of MC-FP. Professionalism (Part I) requires a currently valid, full, and unrestricted license to practice medicine in the United States or Canada. Cognitive Expertise (Part III) involves the successful completion of a cognitive examination.

After a Diplomate has entered MC-FP, all components must be completed to be eligible to sit for the examination. Failure to pass the cognitive examination by the end of the MC-FP cycle results in the loss of certification. To begin MC-FP or to keep track of MC-FP progress, Diplomates may visit the ABFM Web site at http://www.theabfm.org and login to the physician's portfolio section. The ABFM has updated its Web site to reflect the 7-year or 10-year track chosen by the Diplomate.

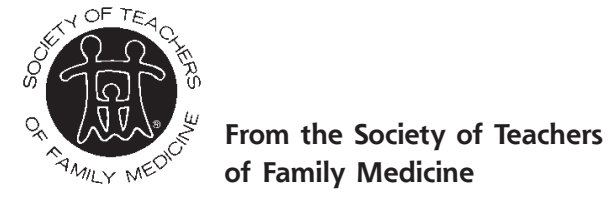

Ann Fam Med 2008:377-378. DOI: 10.1370/afm.878.

\section{STFM AND THE STFM FOUNDATION ANNOUNCE THE 2008 GROUP PROJECT FUND WINNERS}

In 2008, The STFM Group Project Fund, supported by the STFM Foundation, was established to promote and support innovative educational projects proposed by STFM groups. It encourages STFM Group members to collaboratively plan, develop, implement, evaluate, and disseminate findings from educationally related scholarly projects that benefit group members, STFM, and the discipline of family medicine. STFM Foundation Trustees will set aside $50 \%$ of the undesignated net proceeds of each annual giving campaign to fund these projects.

STFM is happy to announce that 4 projects were funded in 2008. Below is a short description of each project.

\section{PROJECT: Adolescent Health for Primary Care: Development of a Web-Based, Comprehensive, Competency-Based Curriculum}

The project will: 1) develop, implement, and evaluate a curricular instruction plan; 2) develop, implement, and maintain a peer-reviewed database of adolescentrelated teaching resources through a link to STFM's Family Medicine Digital Resources Library; and 3) house the curriculum on the Web to maximize access. STFM Group: Adolescent Health-Francesco Leanza, MD, Beth Israel Residency Program in Urban Family Health, New York, NY, principal investigator

Award: $\$ 10,000$ over 2 years

\section{PROJECT: Overcoming Obstacles to Writing for Family Medicine Educators}

This project will conduct 4 writing workshops open to STFM members, particularly junior, women, Hispanic, and minority faculty designed to support minority faculty, enhance their ability to recruit others to the field, and build capacity for research through strengthening writing ability.

\author{
Jane Ireland STFM Group: Minority and Multicultural \\ Health_Lucy Candib, MD, Family Health Center of \\ Worcester, Worcester, Mass, principal investigator \\ Award: $\$ 10,000$ over 2 years
}


PROJECT: Teaching E-mail Communication in a Residency Program

This project will develop a curriculum to teach residents how best to communicate via e-mail with patients while guarding patient confidentiality, safety, and imparting appropriate information in a suitable time to the correct recipient.

STFM Group: Information Technology-Heather Paladine, MD, University of Southern California Family Medicine Residency, principal investigator

Award: $\$ 4,780$ over 2 years

\section{PROJECT: Outgoing Third-Year Family Medicine Resident Satisfaction}

This project will create and offer to all US and Canadian family medicine residency programs a confidential, objective, self-report questionnaire that will be administered online to graduating third-year residents as a part of the exit interview process.

STFM Group: Behavioral Science-Timothy Spruill, EdD, Florida Hospital East Orlando, Orlando, Fla, principal investigator

Award: $\$ 5,000$ over 2 years

\section{The Application Process}

Any recognized, active STFM Group with an idea for a collaborative educational project that is related to its group's goals can request Group Project funds by submitting a completed Group Project Fund Application Form to STFM. STFM will send a request for proposals annually via e-mail to STFM Group Chairs in October.

\section{Proposal Content}

Projects must relate directly to family medicine education (eg, teaching, curriculum development, evaluation, faculty development) and produce measurable outcomes. Projects may focus on patients, medical students in family medicine settings, or family medicine residents, fellows, faculty, and educators/administrators.

\section{Funding Details}

Projects are funded for a maximum of 2 years, and funding is not renewable. Funds may be budgeted in the categories below. Indirect costs are not provided.

- Required equipment (eg, a laptop computer) and supplies (eg, photocopying).

- Travel (eg, funds to present project outcomes at STFM meetings and/or attend project team meetings)

- Personnel (eg, to purchase a statistical consultant's time). Funds for faculty and/or staff release time must be contributed "in-kind" by departments/programs.

A project may be funded for 1 or 2 years at one of 2 levels:
1) Full Funding: A few proposals of exceptional quality and potential impact may be funded up to $\$ 10,000$ total.

2) Seed Money: to support projects up to $\$ 5,000$ total.

\section{Administrative Structure}

The STFM Board's Executive Committee will administer the Group Project Fund and oversee the assessment of submitted proposals for funding.

For more information about the STFM Group Project Fund or to donate to the STFM Foundation to help support projects like those listed here, visit http://www. stfm.org/foundation.

Traci Nolte, STFM

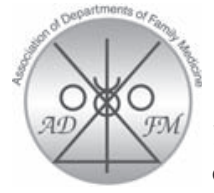

From the Association

of Departments of Family Medicine

Ann Fam Med 2008:378-379. DOI: 10.1370/afm. 876.

\section{COMMUNITY FACULTY: CAUGHT BETWEEN THE DEAN'S OFFICE, ACADEMIC HEALTH CENTERS, DEPARTMENTS AND THE FISCAL REALITIES OF PRIMARY CARE}

Many departments of family medicine are at the threshold of a possible new beginning in undergraduate medical education - a beginning that will provide medical school leaders new opportunities to address anticipated physician workforce shortages and "rightbalance" physician specialty and geographic distribution using innovations in curriculum and national testing standards to achieve these changes. This new beginning will usher in expansion of medical schools' class size as well as the establishment of new medical campuses and schools.

This increase in medical school class size will require academic departments of family medicine to expand and reinforce the distributed community-based (and largely volunteer) physician faculty. These community practices provide learning opportunities for students in family medicine clerkships and often "Introduction to Clinical Medicine" courses. Many of the current family medicine community faculty teaching sites already experience "learner-saturation" not only from family medicine clerkship students, but with students from PA, Nursing, Osteopathic, and international schools competing for community clinical teaching placements.

Academic departments of family medicine are challenged to maintain and now likely rapidly expand 